\title{
Coupled Fixed Points of $\alpha-\Psi$-Contractive Type Multi Functions
}

\section{Mohammadi B* and Alizade E}

Department of Mathematics, Marand Branch, Islamic Azad University, Tehran, Iran

\begin{abstract}
Recently, Samet, Vetro and Vetro introduced $\alpha-\psi$-contractive mappings and gave some results on fixed points of the mappings . In fact, their technique generalized some ordered fixed point results. Also they have proved some results on coupled fixed points of $\alpha-\psi$-contractive mappings. In 1974 Ciric introduced quasicontractive mappings and obtained an important generalization of Banach's contraction principle. Recently Mohammadi, Rezapour and Shahzad have proved some fixed point results on $\alpha-\psi$-contractive and $\alpha-\psi$-quasicontractive multifunction's. By using the main idea of, we give some new results for coupled fixed points of $\alpha-\psi$-contractive multifunction.
\end{abstract}

Keywords: Coupled fixed point; $\alpha-\psi$-Contractive; Multifunction

\section{Introduction}

Denote by $\Psi$ the family of non-decreasing functions $\psi:[0,+\infty) \rightarrow$ $[0,+\infty)$ such that $\sum_{n=1}^{+\infty} \psi^{n}(t)<+\infty$ for all $t>0$. It is well known that $\psi(t)$ $<t$ for all $t>0$.

Definition 1.1: Let $(X, d)$ be a metric space and $\alpha: X \times X \rightarrow[0, \infty)$ be a map. We say that $X$ satisfies condition $\left(C_{\alpha}\right)$, if for any sequence $\left\{x_{n}\right\}$ in $X$, that $x_{n} \rightarrow x$ and $\alpha\left(x_{n}, x_{n+1}\right) \geq 1$ for all $n$, then $\alpha\left(x_{n}, x\right) \geq 1$ for all $\mathrm{n}$. Also, we say that the selfmap $T$ on $X$ is $\alpha$-admissible whenever $\alpha(x, y) \geq$ 1 implies $\alpha\left(T_{x^{\prime}} T_{y}\right) \geq 1$.

Definition 1.2: Let $X$ is an arbitrary space and $\alpha: X^{2} \times X^{2} \rightarrow[0,+\infty)$ a map. A mapping $F: X^{2} \rightarrow X$ is said to be $\alpha$-admissible whenever $\alpha((x$, $y),(u, v)) \geq 1$ implies

$$
\alpha((F(x, y), F(y, x)),(F(u, v), F(v, u))) \geq 1 .
$$

Definition 1.3: Let $(\mathrm{X}, \mathrm{d})$ be a metric space and $\alpha: X^{2} \times X^{2} \rightarrow[0, \infty)$. We say that $X$ satisfies condition $\left(C_{\alpha}\right)$ if for any two sequences $\left\{x_{n}\right\}$ and $\left\{y_{n}\right\}$ in $X$, that $x_{n} \rightarrow x, y_{n} \rightarrow y$ and

$$
\alpha\left(\left(x_{n}, y_{n}\right),\left(x_{n+1}, y_{n+1}\right)\right) \geq 1, \alpha\left(\left(y_{n+1}, x_{n+1}\right),\left(y_{n}, x_{n}\right)\right) \geq 1
$$

For all $\mathrm{n}$, then we have

$\alpha\left(\left(x_{n}, y_{n}\right),(x, y)\right) \geq 1, \alpha\left((y, x),\left(y_{n}, x_{n}\right) \geq 1\right.$

for all $n$.

Definition 1.4: Let $X$ is an arbitrary space and $F: X^{2} \rightarrow X$ is a mapping. We say that $\left(x^{*}, y^{*}\right) \in X^{2}$ is a coupled fixed point of $F$, if we have $F\left(x^{*}, y^{*}\right)=x^{*}$ and $F\left(y^{*}, x^{*}\right)=y^{*}$.

In 2011, Samet, Vetro and Vetro have proved the following theorem [1].

Theorem 1.1: Let $(X, d)$ be complete a metric space, $\alpha: X^{2} \times X^{2} \rightarrow[0$, $\infty)$ a function, $\psi \in \Psi$ and $F: X^{2} \rightarrow X$ an $\alpha$-admissible mapping such that

$$
\alpha((x, y),(u, v)) d(F(x, y), F(u, v)) \leq \frac{1}{2} \psi(d(x, u)+d(y, v)) .
$$

for all $(x, y),(u, v) \in X^{2}$. Assume that the following assertions hold.

(i) There exists $\left(x_{0}, y_{0}\right) \in X^{2}$ such that

$$
\begin{aligned}
& \alpha\left(\left(x_{0}, y_{0}\right),\left(F\left(x_{0}, y_{0}\right), F\left(y_{0^{\prime}}, x_{0}\right)\right)\right) \geq 1, \\
& \alpha\left(\left(F\left(y_{0}, x_{0}\right), F\left(x_{0^{\prime}}, y_{0}\right)\right),\left(y_{0}, x_{0}\right)\right) \geq 1 .
\end{aligned}
$$

(ii) Either $\mathrm{F}$ is continuous or $X$ satisfies condition $\left(C_{\alpha}^{*}\right)$. Then $\mathrm{F}$ has a coupled fixed point in $X^{2}$.
Let $(X, d)$ be a metric space. Define the metric $\delta$ on $X^{2}$ by $\delta((x, y)$, $(u, v))=d(x, u)+d(y, v)$, for all $(x, y),(u, v) \in X^{2}$. Also if $F: X^{2} \rightarrow X$ then put [2].

$m((x, y),(u, v))=\max \{\delta((x, y),(u, v)), \delta((x, y),(F(x, y), F(y, x)))$, $\delta((u, v),(F(u, v), F(v, u)))$

$$
\left.\frac{1}{2}[\delta((x, y),(F(u, v), F(v, u)))+\delta((u, v),(F(x, y), F(y, x)))]\right\},
$$

for all $(x, y),(u, v) \in X^{2}$. It is easy to see that $m((x, y),(u, v))=m((v, u)$, $(y, x))$. Recently Rezapour and H. Asl have extended theorem 1.1 to quasi-contractions as follow [3].

Theorem 1.2: Let $(X, d)$ be a complete metric space, $\alpha: X^{2} \times X^{2} \rightarrow$ $[0,+\infty)$ a function, $\psi \in \Psi$ and $F: X^{2} \rightarrow X$ an $\alpha$-admissible mapping such that [4]

$$
\alpha((x, y),(u, v)) d(F(x, y), F(u, v)) \leq \frac{1}{2} \psi(m((x, y),(u, v))) .
$$

for all $(x, y),(u, v) \in X^{2}$. Assume that the following assertions hold. (i) There exists $\left(x_{0}, y_{0}\right) \in X^{2}$ such that

$$
\begin{aligned}
& \alpha\left(\left(x_{0}, y_{0}\right),\left(F\left(x_{0}, y_{0}\right), F\left(y_{0^{\prime}}, x_{0}\right)\right)\right) \geq 1, \\
& \alpha\left(\left(F\left(y_{0}, x_{0}\right), F\left(x_{0^{0}}, y_{0}\right)\right),\left(y_{0}, x_{0}\right)\right) \geq 1 .
\end{aligned}
$$

(ii) Either $\mathrm{F}$ is continuous or $\psi$ is right upper semi continuous and $X$ satisfies condition $\left(C_{\alpha}^{*}\right)$.

Then $\mathrm{F}$ has a coupled fixed point in $X^{2}$.

Definition 1.5: Let $(X, d)$ be a metric space and $F: X^{2} \rightarrow X$. We say that $F$ is orbitally continuous if for any two sequences $\left\{x_{n}\right\}$ and $\left\{y_{n}\right\}$ in $\mathrm{X}$, that $x_{n} \rightarrow x, y_{n} \rightarrow y$ and $x_{n+1}=F\left(x_{n}, y_{n}\right), y_{n+1}=F\left(y_{n}, x_{n}\right)$, then $F\left(x_{n}, y_{n} \rightarrow F(x, y)\right.$.

Obviously theorem 1.2 is true if $F$ be orbitally continuous instead of continuity. Now we give the following example to show that theorem 1.2 is a real generalization of theorem 1.1, which is there exist mappings

${ }^{*}$ Corresponding author: Mohammadi B, Department of Mathematics, Marand Branch, Islamic Azad University, Tehran, Iran, Tel: 9821479111; E-mail: bmohammadi@marandiau.ac.ir

Received February 18, 2014; Accepted April 25, 2015; Published May 15, 2015

Citation: Mohammadi B, Alizade E (2015) Coupled Fixed Points of $\alpha-\Psi$ Contractive Type Multi Functions. J Appl Computat Math 4: 215. doi:10.4172/21689679.1000215

Copyright: ( 2015 Mohammadi B, et al. This is an open-access article distributed under the terms of the Creative Commons Attribution License, which permits unrestricted use, distribution, and reproduction in any medium, provided the original author and source are credited. 
Citation: Mohammadi B, Alizade E (2015) Coupled Fixed Points of $\alpha-\Psi$-Contractive Type Multi Functions. J Appl Computat Math 4: 215. doi:10.4172/2168-9679.1000215

Page 2 of 5

that we can use theorem 1.2, but we can't use theorem 1.1 for them [5].

\section{Example 1.6:}

Let $\quad M 1=\left\{\frac{m}{n}: m=0,1,3,9, \ldots\right.$ and $\left.n=3 k+1(k \geq 0)\right\}$, $M 2=\left\{\frac{m}{n}: m=1,3,9,27, \ldots\right.$ and $\left.n=3 k+2(k \geq 0)\right\}$. Set $M=M 1 \cup M 2$, $d(x, y)=|x-y|$ and define $F: M^{2} \rightarrow M$ by

$$
F(x, y)= \begin{cases}3 x / 13 & x, y \in M_{1}, x \geq y \\ x / 8 & x, y \in M_{2}, x \geq y \\ 0 & \text { otherwise }\end{cases}
$$

and $\alpha: M^{2} \times M^{2} \rightarrow[0,+\infty)$ by

$$
\alpha((x, y),(u, v))=\left\{\begin{array}{l}
1(x, y),(u, v) \in M_{1}^{2} \cup M_{2}^{2}, x \geq y, u \geq v \\
0 \text { otherwise. }
\end{array}\right.
$$

If $(x, y) \in M_{1}^{2}, x \geq y$ and $(u, v) \in M_{2}^{2}, u \geq v$, then

$$
d(F(x, y), F(u, v))=\left|\frac{3 x}{13}-\frac{u}{8}\right|=\frac{3}{13}\left|x-\frac{13 u}{24}\right| \text {. }
$$

Now we consider two cases. If $x>\frac{13}{24} u$, then we have

$$
\begin{aligned}
& \frac{3}{13}\left|x-\frac{13 u}{24}\right|=\frac{3}{13}\left(x-\frac{13 u}{24}\right) \leq \frac{3}{13}\left(x-\frac{u}{8}\right)=\frac{1}{2}\left(\frac{12}{13}\right) \frac{d(x, F(u, v))}{8} . \\
& \left.\leq \frac{1}{2}\left(\frac{12}{13}\right) \frac{\delta(x, \mathrm{y}, F(u, v), F(u, v)))}{2} \leq \frac{1}{2}\left(\frac{12}{13}\right) \mathrm{m}(\mathrm{x}, \mathrm{y}),(\mathrm{u}, \mathrm{v})\right) .
\end{aligned}
$$

Hence

$\left.d(F(\mathrm{x}, \mathrm{y}), F(u, v)) \leq \frac{1}{2}\left(\frac{12}{13}\right) \mathrm{m}(\mathrm{x}, \mathrm{y}),(\mathrm{u}, \mathrm{v})\right)$.

If $x<\frac{13}{24} u$, then

$\frac{3}{13}\left|x-\frac{13 u}{24}\right|=\frac{3}{13}\left(\frac{13 u}{24}-x\right) \leq \frac{3}{13}(u-x)$

$\left.\left.\leq \frac{1}{2}\left(\frac{6}{13}\right) \delta(x, \mathrm{y}),(u, v)\right) \leq \frac{1}{2}\left(\frac{12}{13}\right) \mathrm{m}(\mathrm{x}, \mathrm{y}),(\mathrm{u}, \mathrm{v})\right)$.

Hence

$\left.d(F(\mathrm{x}, \mathrm{y}), F(u, v)) \leq \frac{1}{2}\left(\frac{12}{13}\right) \mathrm{m}(\mathrm{x}, \mathrm{y}),(\mathrm{u}, \mathrm{v})\right)$.

If $(x, y),(u, v) \in M_{1}^{2}, x \geq y, u \geq v$, then

$\left.d(F(\mathrm{x}, \mathrm{y}), F(u, v))=\left|\frac{3 x}{13}-\frac{3 u}{13}\right|=\frac{3}{13} \mathrm{~d}(x, u) \leq \frac{1}{2}\left(\frac{12}{13}\right) \mathrm{m}(\mathrm{x}, \mathrm{y}),(\mathrm{u}, \mathrm{v})\right)$.

If $(x, y),(u, v) \in M_{2}^{2}$, then

$\left.d(F(\mathrm{x}, \mathrm{y}), F(u, v))=\left|\frac{x}{8}-\frac{u}{8}\right|=\frac{1}{8} \mathrm{~d}(x, u) \leq \frac{1}{2}\left(\frac{12}{13}\right) \mathrm{m}(\mathrm{x}, \mathrm{y}),(\mathrm{u}, \mathrm{v})\right)$.

Now put $\psi(t)=\frac{12 t}{13}$, for all $t \geq 0$, and then we see that

$\alpha((x, y),(u, v)) d(F(x, y), F(u, v)) \leq \frac{1}{2} \psi(m((x, y),(u, v)))$,

for all $(x, y),(u, v) \in M^{2}$. Also

$\alpha((1,1),(F(1,1), F(1,1)))=\alpha((1,1),(3 / 13,3 / 13))=1$,

$\alpha((F(1,1), F(1,1)),(1,1))=\alpha((3 / 13,3 / 13),(1,1))=1$.
To show that $F$ is $\alpha$-admissible, assume $\alpha((x, y),(u, v)) \geq 1$. Then $(x, y),(u, v) \in M_{1}^{2} \cup M_{2}^{2}, x \geq y, u \geq v$. Hence either $x>y$ and $F(y$, $x)=0$ or $x=y$ and $F(x, y) F(y, x)$. However $F(x, y) \geq F(y, x)$. Similarly $F(u, v) \geq F(v, u)$. On the other hand $F(x, y), F(y, x), F(u, v), F(v, u)$ $\in M_{1}$. Hence

$\alpha((F(x, y), F(y, x)),(F(u, v), F(v, u))) \geq 1$.

It is easy to check that $\mathrm{F}$ is orbitally continuous. Now by theorem 1.2 we can say that $F$ has a coupled fixed point in $X^{2}$. In fact $(0,0)$ is a coupled fixed point of $F[6]$.

Now, we show that we cannot apply theorem 1.1 in this example. To see this put [7]

$$
\begin{aligned}
& x=y=9, u=\frac{243}{26}, v=\frac{243}{29} \text {. Then } \\
& \alpha((x, y),(u, v)) d(F(x, y), F(u, v))=\left|\frac{27}{13}-\frac{243}{26 \times 8}\right|=\frac{189}{208}=0.9 .
\end{aligned}
$$

On the other hand

$$
\begin{aligned}
& \frac{1}{2} \psi(\delta((x, y),(u, v))) \leq \frac{1}{2} \delta((x, y),(u, v))=\frac{1}{2}(|x-u|+|y-v|) \\
& \left.\frac{1}{2}\left|9-\frac{243}{26}\right|+\left|9-\frac{243}{26}\right|\right)=\frac{729}{1508}=0.48 .
\end{aligned}
$$

Hence

$$
\alpha((x, y),(u, v)) d(F(x, y), F(u, v))>\frac{1}{2} \psi(\delta((x, y),(u, v))) .
$$

Let $(X, d)$ be a metric space and $C B(X)$ is the set of all nonempty closed bounded subsets of $X, \alpha: X \times X \rightarrow[0, \infty)$ a mapping and $T$ : $X \rightarrow C B(X)$ a multifunction. We say that $T$ is $\alpha$-admissible whenever for each $x \in X$ and $y \in T x$ with $\alpha(x, y) \geq 1$ we have $\alpha(y, z) \geq 1$ for all $z \in T y([4])$. Recall that $T$ is continuous whenever $H\left(T x_{n}, T x\right) \rightarrow 0$ for all sequence $\left\{x_{n}\right\}$ in $X$ with $x_{n} \rightarrow x$, where $H$ is the Hausdorff metric on $C B(X)$ defined by $H(A, B)=\max \left\{\sup _{x} \in_{A} d(x, B)\right.$, sup $\left.\in_{B} d(y, A)\right\}$, for all $A, B \in C B(X)$. Also we say that $T$ is orbitally continuous whenever $H$ $\left(T x_{n}, T_{x}\right) \rightarrow 0$ for all sequence $\left\{x_{n}\right\}$ in $X$ with $x_{n+1} \in T x_{n}$ for all $n$ and $x_{n}$ $\rightarrow x$. Recently Mohammadi, Rezapour and Shahzad have proved the following lemma [8].

Lemma 1.3: ([4] Let $(X, d)$ be a complete metric space, $\alpha: X \times X \rightarrow$ $[0, \infty)$ a function, $\psi \in \Psi$ a strictly increasing map and $T: X \rightarrow C B(X)$ an $\alpha$-admissible multifunction such that $\alpha(x, y) H(T x, T y) \leq \psi(d(x$, $y)$ ) for all $x, y \in X$ and there exist $x_{0} \in X$ and $x_{1} \in T x_{0}$ with $\alpha\left(x_{0}, x_{1}\right) \geq$ 1. If $T$ is continuous or $X$ satisfies the condition $\left(C_{\alpha}\right)$, then $T$ has a fixed point. Note that if $T$ be orbitally continuous instead of continuity, then the lemma1.3 is also true [2].

\section{Main Results}

Now, we are ready to state and prove our main results.

Definition 2.1: Let $X$ is an arbitrary space and $\alpha: X^{2} \times X^{2} \rightarrow[0$, $+\infty)$ a map. A multifunction $F: X^{2} \rightarrow C B(X)$ is said to be a-admissible whenever if $(x, y) \in X^{2},(u, v) \in F(x, y) \times F(y, x)$ and $\alpha((x, y),(u, v)) \geq$ $1, \alpha((v, u),(y, x)) \geq 1$, then $\alpha((u, v),(w, z)) \geq 1, \alpha((z, w),(v, u)) \geq 1$, for all $(w, z) \in F(u, v) \times F(v, u)$.

Definition 2.2: Let $(X, d)$ be a metric space and $F: X^{2} \rightarrow C B(X)$ is a multifunction. We say that $\left(x^{*}, y^{*}\right) \in X^{2}$ is a coupled fixed point of $\mathrm{F}$ if we have $x^{*} \in F\left(x^{*}, y^{* *}\right)$ and $y^{*} \in F\left(y^{*}, x^{*}\right)$.

Theorem 2.1: Let $(X, d)$ be a complete metric space, $\alpha: X^{2} \times X^{2} \rightarrow[0$, 
Citation: Mohammadi B, Alizade E (2015) Coupled Fixed Points of $\alpha-\Psi$-Contractive Type Multi Functions. J Appl Computat Math 4: 215. doi:10.4172/2168-9679.1000215

Page 3 of 5

$+\infty)$ a function, $\psi \in \Psi$ a strictly increasing map and $\mathrm{F}: \mathrm{X}_{2} \rightarrow \mathrm{CB}(\mathrm{X})$ an $\alpha$-admissible multifunction such that [7]

$$
\alpha((x, y),(u, v)) H(F(x, y), F(u, v)) \leq \frac{1}{2} \psi(d(x, u)+d(y, v)) .
$$

for all $(x, y),(u, v) \in X^{2}$. Assume that the following assertions hold. that

(i) There exists $\left(x_{0}, y_{0}\right) \in X_{2}$ and $\left(x_{1}, y_{1}\right) \in F\left(x_{0}, y_{0}\right) \times F\left(y_{0}, x_{0}\right)$ such

$\alpha\left(\left(x_{0}, y_{0}\right),\left(x_{1}, y_{1}\right)\right) \geq 1, \quad \alpha\left(\left(y_{1}, x_{1}\right),\left(y_{0}, x_{0}\right)\right) \geq 1$.

(ii) Either $F$ is continuous or $X$ satisfies condition $\left(C^{*}\right)$. Then $\mathrm{F}$ has a coupled fixed point in $X^{2}$.

Proof Define $\beta: X_{2} \times X_{2} \rightarrow[0,+\infty)$ by

$\beta\left(\left(\xi_{1}, \xi_{2}\right),\left(\eta_{1}, \eta_{2}\right)\right)=\min \left\{\alpha\left(\left(\xi_{1}, \xi_{2}\right),(\eta 1, \eta 2)\right), \alpha\left(\left(\eta_{1}, \eta_{2}\right),\left(\xi_{1}, \xi_{2}\right)\right)\right\}$

for all

$\xi=\left(\xi_{1}, \xi_{2}\right) \in X^{2}, \eta=\left(\eta_{1}, \eta_{2}\right) \in X^{2}$.

Also suppose $T: X^{2} \rightarrow C B\left(X^{2}\right)$ is defined by $T(x, y)=F(x, y) \times F$ $(y, x)$. Obviously the metric space $\left(X^{2}, \delta\right)$ is complete. Now since $F$ is $\alpha$-admissible, it is easy to see that $T$ is $\beta$-admissible. Also by assumption

$$
\begin{aligned}
& \alpha((x, y),(u, v)) H(F(x, y), F(u, v)) \leq \frac{1}{2} \psi(d(x, u)+d(y, v)), \\
& \alpha((\mathrm{v}, \mathrm{u}),(\mathrm{y}, \mathrm{x})) H(F(\mathrm{v}, \mathrm{u}), F(\mathrm{y}, \mathrm{x})) \leq \frac{1}{2} \psi(d(\mathrm{v}, \mathrm{y})+d(\mathrm{u}, \mathrm{x})) .
\end{aligned}
$$

for all $(x, y),(u, v) \in X^{2}$. By adding the above two relations we obtain.

$\beta((x, y),(u, v))[H(F(x, y), F(u, v))+H(F(v, u), F(y, x))] \leq \psi(\delta((x$, $y),(u, v)))$.

Assume that $H_{\delta}$ is the Hausdorff metric on $\left(X^{2}, \delta\right)$. We should show that

$H_{\delta}(T(x, y), T(u, v)) \leq H(F(x, y), F(u, v))+H(F(v, u), F(y, x))$.

For this we have

$$
\begin{aligned}
& H_{\delta}(T(x, y), T(u, v))=H_{\delta}(F(x, y) \times F(y, x), F(u, v) \times F(v, u)) \\
& =\max \left\{\sup _{\left(\xi_{1}, \xi_{2}\right) \in F(x, y) \times F(y, x)} \delta\left(\left(\xi_{1}, \xi_{2}\right), F(u, v) \times F(v, u)\right),\right. \\
& \left.\sup _{\left(\eta_{1}, \eta_{2}\right) \in F(u, v) \times F(v, u)} \delta\left(\left(\eta_{1}, \eta_{2}\right), F(x, y) \times F(y, x)\right)\right\} .
\end{aligned}
$$

$$
\begin{aligned}
\delta\left(\left(\xi_{1}, \xi_{2}\right), F(u, v) \times F(v, u)\right) & =\inf _{\left(\eta_{1}, \eta_{2}\right) \in F(u, v) \times F(v, u)} \delta\left(\left(\xi_{1}, \xi_{2}\right),\left(\eta_{1}, \eta_{2}\right)\right), \\
& =\inf _{\substack{\left(\eta_{1}, \eta_{2}\right) \in F(u, v) \times F(v, u)\\
}}\left[d\left(\xi_{1}, \eta_{1}\right)+d\left(\xi_{2}, \eta_{2}\right)\right] . \\
& \inf d\left(\xi_{1}, \eta_{1}\right)+\underset{\eta_{1 \in F(u, v)}}{\inf d\left(\xi_{2}, \eta_{2}\right)}{ }_{\eta_{2} \in F(v, u)}
\end{aligned}
$$

$=d\left(\xi_{1}, F(u, v)+d\left(\xi_{2}, F(v, u) \leq H(F(x, y), F(u, v))+H(F(y, x), F(v, u))\right.\right.$.

Similarly for $\left(\eta_{1}, \eta_{2}\right) \in F(u, v) \times F(v, u)$ we have $(v, u))$

$\delta\left(\left(\eta_{1}, \eta_{2}\right), F(x, y) \times F(y, x)\right) \leq H(F(x, y), F(u, v))+H(F(y, x), F$

Hence (5) holds. By (4) and (5) we have $\beta((x, y),(u, v)) H_{\delta}(T(x, y), T(u, v)) \leq \psi(\delta((x, y),(u, v)))$.

Hence for any $\xi=\left(\xi_{1}, \xi_{2}\right) \in X^{2}, \eta=\left(\eta_{1}, \eta_{2}\right) \in X^{2}$ we have

$\beta(\xi, \eta) H_{\delta}(T \xi, T \eta) \leq \psi(\delta(\xi, \eta))$.

So $T: X^{2} \rightarrow C B\left(X^{2}\right)$ is a $\beta$ - $\psi$-contractive multifunction. Put $P_{0}=\left(x_{0}\right.$, $\left.y_{0}\right), P_{1}=\left(x_{1}, y_{1}\right)$. Then $P 1 \in T \mathrm{P}_{0}, \beta\left(\mathrm{P}_{0}, \mathrm{P}_{1}\right) \geq 1$. Now let $\mathrm{F}$ be continuous. We show that $T$ is continuous. To see this let $\left\{\left(x_{n^{n}}, y_{n}\right)\right\}$ be a sequence in $X^{2}$ such that $\delta\left(\left(x, y_{n}\right),(x, y)\right) \rightarrow 0$. Then $d(x, x)+d(y, y) \rightarrow 0$ and hence $d\left(x_{n}, x\right) \rightarrow 0, d\left(y_{n}, y\right) \rightarrow 0$. Now since $\mathrm{F}$ is continuous, hence

$H\left(F\left(x_{n}, y_{n}\right), F(x, y)\right) \rightarrow 0, H\left(F\left(y_{n}, x_{n}\right), F(y, x)\right) \rightarrow 0$.

Therefore $x) \rightarrow 0$

$H_{\delta}\left(T\left(x_{n}, y_{n}\right), T(x, y)\right) \leq H\left(F\left(x_{n}, y_{n}\right), F(x, y)\right)+H\left(F\left(y_{n}, x_{n}\right), F(y\right.$,

This shows that $T: X^{2} \rightarrow C\left(X^{2}\right)$ is continuous.

Also if $X$ has $\left(C_{\alpha}^{*}\right)$ condition, it is easy to see that $X^{2}$ has condition $\mathrm{C}_{\beta}$. Now all of the conditions of lemma 1.3 hold. Hence by the lemma there exists $\left(x^{*}, y^{*}\right) \in X^{2}$ such that $\left(x^{*}, y^{*}\right) \in T\left(x^{*}, y^{*}\right)=F\left(x^{*}, y^{*}\right) \times F\left(y^{*}\right.$, $\left.x^{*}\right)$, hence $x^{*} \in F\left(x^{*}, y^{*}\right), y^{*} \in F\left(y^{*}, x^{*}\right)$. That is $\left(x^{*}, y^{*}\right)$ is a coupled fixed point of $F$ in $X^{2}$. Now by using the following simple definitions we want to prove another version of theorem 2.1.

Definition 2.3: Let $(X, d)$ is a metric space and $\alpha: X^{2} \times X^{2} \rightarrow[0$, $+\infty)$ is a map. A multifunction $F: X^{2} \rightarrow C B(X)$ is said to be modified $\alpha$-admissible whenever if $(x, y) \in X^{2},(u, v) \in F(x, y) \times F(y, x)$ and $\alpha((x$, $y),(u, v)) \geq 1$, then $\alpha((u, v),(w, z)) \geq 1$, for all $(w, z) \in F(u, v) \times F(v, u)$.

Definition 2.4: Let $(X, d)$ be a metric space and $\alpha: X 2 \times X 2 \rightarrow[0$, $\infty)$. We say that $X$ satisfies condition $\left(B_{\alpha}^{*}\right)$ if for any two sequences $\left\{x_{n}\right\}$ and $\left\{y_{n}\right\}$ in $X$, that $x_{n} \rightarrow x, y_{n} \rightarrow y$ and $\alpha\left(\left(x_{n}, y_{n}\right),\left(x_{n+1}, y_{n+1}\right) \geq 1\right.$ for all $n$, then we have $\alpha\left(\left(x_{n}, y_{n}\right),(x, y)\right) \geq 1$ for all $\mathrm{n}$.

Theorem 2.2: Let $(X, d)$ be a complete metric space, $\alpha: X^{2} \times X^{2} \rightarrow[0$, $+\infty)$ a function, $\psi \in \Psi$ a strictly increasing map and $F: X^{2} \rightarrow C B(X)$ a modified $\alpha$-admissible multifunction such that

$$
\alpha((x, y),(u, v)) H(F(x, y), F(u, v)) \leq \frac{1}{2} \psi(d(x, u)+d(y, v)) .
$$

For all $(x, y),(u, v) \in X^{2}$. Assume that the following assertions hold. that

(i) There exist $\left(x_{0}, y_{0}\right) \in X^{2}$ and $\left(x_{1}, y_{1} \in F\left(x_{0}, y_{0}\right) \times F\left(y_{0}, x_{0}\right)\right.$ such $A\left(\left(x_{0}, y_{0}\right),(x 1, y 1)\right) \geq 1, \alpha\left(\left(y_{0}, x_{0}\right),\left(y_{1}, x_{1}\right)\right) \geq 1$.

(ii) Either $F$ is continuous or $X$ satisfies condition $\left(B_{\alpha}^{*}\right)$.

Then $F$ has a coupled fixed point in $X^{2}$.

Proof Define $\beta: X^{2} \times X^{2} \rightarrow[0,+\infty)$ by

$\beta\left(\left(\xi_{1}, \xi_{2}\right),\left(\eta_{1}, \eta_{2}\right)\right)=\min \left\{\alpha\left(\left(\xi_{1}, \xi_{2}\right),\left(\eta_{1}, \eta_{2}\right)\right), \alpha\left(\left(\xi_{2}, \xi_{1},\left(\eta_{2}, \eta_{1}\right)\right)\right\}\right.$

for all

$\xi=\left(\xi_{1}, \xi_{2}\right) \in X^{2}, \eta=\left(\eta_{1}, \eta_{2}\right) \in X^{2}$

The remain of proof is completely similar to proof of theorem 2.1

Example 2.5: Let $X$ be the space of real numbers with the usual metric $d(x, y)=|x-y|$ and define $F: X^{2} \rightarrow C B(X)$ by

$F(x, y)= \begin{cases}{\left[0, \frac{x-y}{3}\right]} & x \geq y \\ \{0\} & x<y\end{cases}$

Also define $\alpha: X^{2} \times X^{2} \rightarrow[0,+\infty)$ by 


$$
\alpha((x, y),(u, v))= \begin{cases}1 & x \geq y, u \geq v \\ 0 & \text { otherwise }\end{cases}
$$

If $(x, y),(u, v) \in X^{2}$ and $x \geq y, u \geq v$, then

$$
\begin{aligned}
& H(F(x, y), F(u, v))=H\left(\left[0, \frac{x-y}{3}\right],\left[0, \frac{u-v}{3}\right]\right) \\
& \left.=\frac{1}{3}|x-y-(u-v)| \leq \frac{1}{2}\left(\frac{2}{3}\right)\right)(\mathrm{d}(\mathrm{x}, \mathrm{u})+\mathrm{d}(\mathrm{y}, \mathrm{v})) .
\end{aligned}
$$

Now put $\psi(t)=\frac{2 t}{3}$. We see that

$$
\alpha((x, y),(u, v)) H(F(x, y), F(u, v)) \leq \frac{1}{2} \psi(d(x, u)+d(y, v)) .
$$

Also for $\left(x_{0}, y_{0}\right)=(1,1),\left(x_{1}, y_{1}\right)=(0,0)$ we have

$$
\begin{aligned}
& F\left(x_{0}, y_{0}\right)=F\left(y_{0}, x_{0}\right)=\{0\},\left(x_{1}, y_{1}\right)=(0,0) \in\{(0,0)\}=F\left(x_{0^{\prime}} y_{0}\right) \times F\left(y_{0^{\prime}}, x_{0}\right), \\
& \alpha\left(\left(\mathrm{x}_{0}, \mathrm{y}_{0}\right),\left(\mathrm{x}_{1}, \mathrm{y}_{1}\right)\right)=\alpha((1,1),(0,0))=1, \\
& \alpha\left(\left(\mathrm{y}_{0}, \mathrm{x}_{0}\right),\left(\mathrm{y}_{1}, \mathrm{x}_{1}\right)\right)=\alpha((1,1),(0,0))=1 .
\end{aligned}
$$

Now let $(x, y) \in X^{2},(u, v) \in F(x, y) \times F(y, x)$ and $\alpha((x, y),(u, v))$ $\geq 1$. Then $x \geq y, u \geq v$. Hence $F(v, u)=\{0\}$. Now if $(w, z) \in F(u, v) \times F$ $(v, u)$, then $w \geq 0=z$. Therefore $\alpha((u, v),(w, z)) \geq 1$.This shows that $\mathrm{F}$ is modified $\alpha$-admissible. It is easy to see that $F$ is continuous. Hence by theorem 2.2, F has a coupled fixed point in $X^{2}$. For example $(0,0)$ is a coupled fixed point of $F$.

Example 2.6: Let $X$ be the space of real numbers with the usual metric $d(x, y)=|x-y|$ and define $F: X^{2} \rightarrow C B(X)$ by $F(x, y)=[0,2|x-y|]$ for all $x, y \in X$. Also define $\alpha: X^{2} \times X^{2} \rightarrow[0, \infty)$ by

$$
\alpha((x, y),(u, v))= \begin{cases}\frac{1}{8} & (x, y, u, v) \neq(0,0,0,0) \\ 1 & \mathrm{x}=\mathrm{y}=\mathrm{u}=\mathrm{v}=0\end{cases}
$$

Now put $\psi(t)=\frac{t}{2}$. We see that

$$
\alpha((x, y),(u, v)) H(F(x, y), F(u, v)) \leq \frac{1}{2} \psi(d(x, u)+d(y, v)) .
$$

Also for $\left(x_{0}, y_{0}\right)=\left(x_{1}, y_{1}\right)=(0,0)$ we have

$$
F\left(x_{0}, y_{0}\right)=F\left(y_{0}, x_{0}\right)=\{0\},\left(x_{1}, y_{1}\right)=(0,0) \in\{(0,0)\}=F\left(x_{0}, y_{0}\right) \times F\left(y_{0},\right.
$$

$\left.x_{0}\right), \alpha\left(\left(x_{0}, y_{0}\right),\left(x_{1}, y_{1}\right)\right)=\alpha((0,0),(0,0))=1$,

$$
\alpha\left(\left(y_{0}, x_{0,},\left(y_{1}, x_{1}\right)\right)=\alpha((0,0),(0,0))=1 .\right.
$$

It is easy to see that $F$ is modified $\alpha$-admissible. Obviously $\mathrm{F}$ is continuous. Hence by theorem $2.2, F$ has a coupled fixed point in $X^{2}$. For example $(0,0)$ is a coupled fixed point of $F$. Note that coupled fixed point of $F$ is not unique for example $(2,1)$ is a coupled fixed point of $\mathrm{F}$ too. In fact for any $x, y \geq 0$ that $x \geq 2 y$ or $y \geq 2 x,(x, y)$ is a coupled fixed point of $F$.

Corollary 2.3: Let $(X, d)$ be a complete metric space and $\preceq$ be an order on $X^{2}$. Suppose $\psi \in \Psi$ a strictly increasing map and $F: X^{2} \rightarrow$ $C B(X)$ a multifunction such that

$$
H(F(x, y), F(u, v)) \leq \frac{1}{2} \psi(d(x, u)+d(y, v)),
$$

for all comparable elements $(x, y),(u, v) \in X^{2}$. Assume that the following assertions hold.

(i) If $(x, y) \in X^{2},(u, v) \in F(x, y) \times F(y, x)$ and $(x, y),(u, v)$ are comparable, then $(u, v),(w, z)$ are comparable, for all $(w, z) \in F(u, v)$ $\times F(v, u)$.

(ii) There exist $\left(x_{0^{\prime}} y_{0}\right) \in X^{2}$ and $\left(x_{1}, y_{1}\right) \in F\left(x_{0}, y_{0}\right) \times F\left(y_{0}, x_{0}\right)$ such that $\left(\mathrm{x}_{0}, \mathrm{y}_{0}\right),\left(\mathrm{x} 1, \mathrm{y}_{1}\right)$ are comparable and $\left(\mathrm{y}_{0}, \mathrm{x}_{0}\right),\left(\mathrm{y}_{1}, \mathrm{x}_{1}\right)$ are comparable.

(iii) Either $F$ is continuous or for any two sequences $\left\{x_{n}\right\}$ and $\left\{y_{n}\right\}$ in $X$, that $x_{n} \rightarrow x, y_{n} \rightarrow y$ and $\left(x_{n}, y_{n}\right),\left(x_{n+1}, y_{n+1)}\right.$ are comparable for all $n$, then $\left(x_{n}, y_{n}\right),(x, y)$ are comparable for all $\mathrm{n}$.

Then $\mathrm{F}$ has a coupled fixed point in $\mathrm{X}^{2}$.

Proof Define $\alpha: X^{2} \times X^{2} \rightarrow[0,+\infty)$ by $\alpha((x, y),(u, v))=1$ if $(x, y),(u, v)$ are com- parable and $\alpha((x, y),(u, v))=0$ otherwise and apply theorem 2.2

Corollary 2.4: Let $(\mathrm{X}, \mathrm{d})$ be a complete metric space and $\leq$ be an order on $X^{2}$. Fix $\left(x^{*}, y^{*}\right) \in X^{2}$. Suppose $\psi \in \Psi$ a strictly increasing map and $F: X^{2} \rightarrow C B(X)$ a multifunction such that $H(F(x, y), F(u, v)) \leq \frac{1}{2} \psi(d(x, u)+d(y, v))$, for all comparable elements $(x$, $y),(u, v) \in X^{2}$ with $(x, y)$. Assume that the following assertions hold.

(i) If $(x, y) \in X^{2},(u, v) \in F(x, y) \times F(y, x)$ and $(x, y),(u, v)$ are comparable with $\left(x^{*}, y^{*}\right)$, then $(u, v),(w, z)$ are comparable with $\left(x^{*}, y^{*}\right)$, for all $(w, z) \in F(u, v) \times F(v, u)$.

(ii) There exist $\left(x_{0^{\prime}} y_{0}\right) \in X^{2}$ and $\left(x_{1}, y_{1}\right) \in F\left(x_{0}, y_{0}\right) \times F\left(y_{0}, x_{0}\right)$ such that $\left(x_{0}, y_{0}\right),\left(x_{1}, y_{1}\right)$ are comparable with $\left(x^{*}, y^{*}\right)$ and $\left(y_{0}, x_{0}\right),\left(y_{1}, x_{1}\right)$ are comparable with $\left(x^{*}, y^{*}\right)$.

(iii) Either $F$ is continuous or for any two sequences $\left\{x_{n}\right\}$ and $\left\{y_{n}\right\}$ in $X$, that $x_{n} \rightarrow x, y_{n} \rightarrow y$ and $\left(x_{n}, y_{n}\right),\left(x_{n+1} y_{n+1)}\right.$ are comparable with $\left(x^{*}, y^{*}\right)$ for all $\mathrm{n}$, then $\left(x_{n}, y_{n}\right),(x, y)$ are comparable with $\left(x^{*}, y^{*}\right)$ for all $\mathrm{n}$.Then $\mathrm{F}$ has a coupled fixed point in $X^{2}$.

Proof Define $\alpha: X^{2} \times X^{2} \rightarrow[0,+\infty)$ by $\alpha((x, y),(u, v))=1$ if $(x, y),(u$, $v)$ are comparable with $\left(x^{*}, y^{*}\right)$ and $\alpha((x, y),(u, v))=0$ otherwise and apply theorem 2.2.

Corollary 2.5: Let $(X, \preceq, d)$ be a partial ordered complete metric space. Suppose $\psi \in \Psi$ a strictly increasing map and $F: X^{2} \rightarrow C B(X)$ a multifunction such that

$$
H(F(x, y), F(u, v)) \leq \frac{1}{2} \psi(d(x, u)+d(y, v)),
$$

for all elements $(\mathrm{x}, \mathrm{y}),(\mathrm{u}, \mathrm{v}) \in X^{2}$ that $x \geq u$ or $y \geq v$.

Assume that the following assertions hold.

(i) If $(x, y) \in X^{2},(u, v) \in F(x, y) \times F(y, x)$ and $x \geq u$ or $y \geq v$, then $u$ $\geq w$ or $v \geq z$, for all $(w, z) \in F(u, v) \times F(v, u)$.

(ii) There exist $\left(x_{0}, y_{0)} \in X^{2}\right.$ and $\left(x_{1}, y_{1}\right) \in F\left(x_{0}, y_{0}\right) \times F\left(y_{0}, x_{0}\right)$ such that $x_{0} \geq x_{1}$ or $y_{0} \geq y_{1}$.

(iii) Either $\mathrm{F}$ is continuous or for any two sequences $\left\{x_{n}\right\}$ and $\left\{y_{n}\right\}$ in $X$, that $x_{n} \rightarrow x, y_{n} \rightarrow y$ and $x_{n} \geq x_{n+1}$ or $y_{n} \geq y_{n+1}$ for all $n$, then $x_{n} \geq x$ or $y_{n} \geq y$ for all $n$.

Then $\mathrm{F}$ has a coupled fixed point in $X^{2}$.

Proof Define $\alpha: X^{2} \times X^{2} \rightarrow[0,+\infty)$ by $\alpha((x, y),(u, v))=1$ if $x \geq u$ or $y \geq v$ are comparable and $\alpha((x, y),(u, v))=0$ otherwise and apply theorem 2.2 .

\section{References}

1. Alikhani H, Rezapour SH, Shahzad N (2013) Fixed points of a new type contractive mappings and multi functions. To appear in Filomat 27: 1315-1319.

2. Ciric LB (1974) A generalization of Banachs contraction principle. Proc Amer Math Soc 45: 267-273.

3. Jachymski J (2011) Equivalent conditions for generalized contractions on (ordered) metric spaces. Nonlinear Analysis 74: 768-774. 


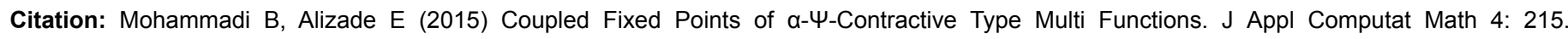
doi:10.4172/2168-9679.1000215

Page 5 of 5

4. Mohammadi B, Rezapour SH, Shahzad N (2013) Some results on fixed points of $\alpha-\psi$-Ciric generalized multi functions. Fixed Point Theory Appl 2013:24.

5. Mohammadi B, Dinu S, Rezapour SH (2013) Fixed points of Suzuki type quasicontractions. U.P.B Sci Bull Series A 75: 3-12.
6. Rezapour SH, AsI HJ (2013) A simple method for obtaining coupled fixed points of $\alpha-\psi$-contractive type mappings. Internat $J$ Analysis.

7. Salimi P, Latif A, Hussain N (2013) Modified $\alpha-\psi$-contractive mappings with applications. Fixed Point Theory Appl 2013:151.

8. Samet B, Vetro C, Vetro P (2012) Fixed point theorems for $\alpha-\psi$-contractive type mappings. Nonlinear Analysis 75: 2154-2165. 